\title{
Self-efficacy for the self-regulation of learning: An examination of a college success strategies course
}

\author{
Brandon M. Agostini \\ West Virginia University
}

Follow this and additional works at: https://researchrepository.wvu.edu/etd

\section{Recommended Citation}

Agostini, Brandon M., "Self-efficacy for the self-regulation of learning: An examination of a college success strategies course" (2010). Graduate Theses, Dissertations, and Problem Reports. 733. https://researchrepository.wvu.edu/etd/733

This Thesis is protected by copyright and/or related rights. It has been brought to you by the The Research Repository @ WVU with permission from the rights-holder(s). You are free to use this Thesis in any way that is permitted by the copyright and related rights legislation that applies to your use. For other uses you must obtain permission from the rights-holder(s) directly, unless additional rights are indicated by a Creative Commons license in the record and/ or on the work itself. This Thesis has been accepted for inclusion in WVU Graduate Theses, Dissertations, and Problem Reports collection by an authorized administrator of The Research Repository @ WVU. For more information, please contact researchrepository@mail.wvu.edu. 


\title{
Self-efficacy for the Self-regulation of Learning: An Examination of a
} College Success Strategies Course

\author{
Brandon M. Agostini
}

\author{
Thesis submitted to the \\ College of Human Resources and Education \\ at West Virginia University \\ in partial fulfillment of the requirements \\ for the degree of
}

\author{
Master of Arts \\ in \\ Educational Psychology
}

Daniel Hursh, Ph.D., Chair

Patricia Haught, Ed.D.

Ernest R. Goeres, Ph.D.

Department of Technology, Learning, and Culture

Morgantown, West Virginia

2010 


\title{
ABSTRACT \\ Self-efficacy for the Self-regulation of Learning: An Examination of a College Success Strategies Course
}

\author{
Brandon M. Agostini
}

Self-efficacy has been shown to be a good predictor of task performance. An area identified as needing further research is the influences of self-efficacy. The objective of this research project was to assess efficacy beliefs related to the regulation of learning for students enrolled in a semester long college success strategies course. This was done to determine if learning about the learning process and skills and behaviors that promote learning would positively influence efficacy beliefs related to the regulation of learning. The college success strategies course was designed to teach students various learning and time management skills. Efficacy beliefs were assessed at three points during the semester. Sixty students completed all three of the assessments $(\mathrm{N}=60)$. The efficacy assessment (Self-efficacy for Learning Form - Abridged) used was chosen because the items it contained targeted abilities focused on in the college success strategies course. Statistically significant differences across assessments were found for three of the items on the assessment. Results offer little evidence to support the idea that learning about learning positively influences efficacy for learning. However, results might suggest that the college success strategies course helped students more accurately appraise their capabilities. 
Self-efficacy can be defined as the beliefs that individuals hold about their capabilities to control their level of functioning and environmental demands (Bandura \& Barbaranelli, 1996). Selfefficacy theory was first introduced by Albert Bandura in 1977. Self-efficacy helps to determine individuals' behavior, thoughts, and emotional reactions in stressful situations (Bandura, 1982). In order to have incentive to act, people must believe that their actions can produce the effects that they want (Bandura \& Barbaranelli 1996). The inability to influence the events and social conditions that affect one's life can lead to feelings of futility and eventually to anxiety. People give up because they do not feel they have the capabilities to do what is required. Attributing one's failures to general and long lasting personal problems constitutes a sense of inefficacy (Bandura, 1982).

Self-efficacy can directly influence an individual's choice of activities. People tend to avoid activities they perceive to be beyond their ability, but they will take on activities they judge themselves capable of managing (Bandura, 1982). Efficacy beliefs determine how much effort people put forth and how long they will maintain that effort in the presence of difficulties (Bandura, 1977). When difficulties are encountered, individuals who seriously doubt their capabilities put forth less effort or give up completely. People with stronger perceived self-efficacy are more likely to continue their efforts until they succeed (Bandura, 1982). Individuals with low self-efficacy are more easily discouraged by failure than those individuals with high self-efficacy (Bandura \& Cervone, 1983). Task persistence is best related to self-efficacy when the task is difficult enough to cause students with low self-efficacy to quit and those with high self-efficacy to continue working because they feel they can master the task (Schunk, 1996).

Self-efficacy is believed to be a much better predictor of performance when the task and measure have the same level of specificity (Finney \& Schraw, 2003). According to Pajares (1996b), self-efficacy is task-specific and measurements of self-efficacy should also be task-specific. This has 
been identified as a problem in the research. Using general or global measures of self-efficacy for a specific task will weaken effects. These broad, general measures of efficacy are really attempting to assess a general feeling of confidence. These measures make it difficult to determine what is really being assessed (Pajares, 1996a).

This has been ignored in many research studies, and it is believed to be the reason that some researchers do not find significant relationships between self-efficacy and a chosen variable. These conclusions may not be accurate because of the difference in specificity. Finney and Schraw (2003) examined self-efficacy in a college statistics course. It was shown that the magnitude of the relationship between performance and statistics self-efficacy was greater than performance and math self-efficacy. The researchers reviewed two previous studies examining statistics self-efficacy that found no significant relationship between self-efficacy and achievement and that finding was attributed to lack of specificity in the measures of self-efficacy. Pajares and Miller (1995) found self-efficacy for solving math problems was a better predictor of performance than efficacy for math-related tasks or efficacy for math-related courses and that finding also supports the necessity of using as specific a measure as possible.

Self-efficacy is not the only factor that influences achievement. Ability, skill, knowledge, and outcome expectations all influence achievement behaviors. High self-efficacy will not produce successful performances when these other factors are lacking (Schunk, 1996). Outcome expectations are the beliefs one holds about the likely outcomes of actions. They are important because students usually take actions that they believe will have positive outcomes. Outcome expectations and selfefficacy are related in that students with high self-efficacy expect and usually produce positive outcomes for their actions. The relationship between self-efficacy and outcome expectations is not automatic (Schunk, 1996). However, Eastman and Marzillier (1984) contended that efficacy and 
outcome expectations are inherently interrelated. They claimed that it was impossible to separate the two and that self-efficacy theory itself is flawed. Numerous research studies in different domains of research have shown otherwise. Bandura (1984) made it clear that human behavior is regulated and determined by numerous factors. It is possible for both efficacy and outcome expectations to account for some of the variance in human behavior.

It is possible for an individual with the same set of skills to have a very poor performance or a very exceptional performance based upon changes in self-efficacy (Bandura, 1993). Ability level and efficacy beliefs both contribute to performance. It is possible to have low ability with high efficacy beliefs and outperform individuals with higher ability and lower efficacy beliefs (Bandura, 1993). Individuals who view ability as an inherent trait show large losses in efficacy beliefs when dealing with problems. Individuals who view ability as something they may acquire stay much more firm in their efficacy beliefs when dealing with problems (Bandura, 1993). However, as previously stated, high self-efficacy will not result in successful performances when skill is very lacking (Schunk, 1996).

The setting of goals may be regulated by self-efficacy. Higher perceived self-efficacy leads individuals to adopt higher goal challenges and maintain a firmer commitment to them. Research has shown that efficacy beliefs may have a large impact on various aspects of human behavior and development including motivation (Bandura, 1993). The goals an individual chooses then have an effect upon that individual's self-efficacy. Goals influence self-efficacy through their properties of specificity, difficulty level, and proximity (Schunk, 1987). Self-motivation is best called upon and maintained through the use of smaller, short-term goals that are easily attained and lead to larger, longterm goals (Bandura, 1982). The level and specificity of goals help to provide standards for which people may evaluate themselves. Explicitly stated goals are more likely than general goals to invoke self-reactive influences for a particular task (Bandura \& Schunk, 1981). Efficacy and motivation are 
likely to be positively influenced when people feel they are making progress toward a goal and becoming more competent. That does not mean that slow progress will lower efficacy or motivation. If students believe that they are capable of doing better by adjusting their approach, their self-efficacy is less likely to be negatively influenced (Schunk, 1989a).

Short-term goals provide immediate incentive and guidance for action. These short-term goals have reciprocal influence upon self-efficacy beliefs. Short-term goals provide people with a frequent way to judge their capabilities. They provide clear benchmarks of progress to verify increasing efficacy beliefs on the path to long-term goals (Bandura, 1982). Distal goals are more difficult to evaluate, and they provide less clear information to individuals than their short-term counterparts (Schunk, 1990). In a study conducted by Bandura and Schunk (1981), individuals who used short-term goals showed substantial increases in perceived self-efficacy and even further gains following a performance posttest.

Without these goals, people have no basis upon which to judge their level of performance. Individuals who were more oriented with long-term goals also showed self-efficacy increases, but these increases were followed by a decrease after the posttest. Those who adopted the short-term goals also showed more gains in persistence than those who adopted long-term goals. Those who developed their skills while using short-term goals were also more likely to accurately judge their own capabilities. However, the short-term focus of the research on goal setting and self-efficacy is a problem. The research is unable to explain academic motivation as a whole. From graduating high school to earning a college degree, many academic goals are long-term goals (Schunk, 1991).

Self-efficacy can be influenced in a number of different ways with the most common being through personal actions and experiences. Verbal persuasion is also commonly used to help people believe they are capable of successfully completing a task. Persuasion is limited in its ability to create 
enduring increases in efficacy beliefs, but it can help lead to successful performances if the appraisals are within realistic bounds (Bandura, 1982). Efficacy beliefs can be influenced through vicarious experiences as well.

Watching others similar to one's self succeed can raise the efficacy beliefs of observers who then believe they are capable of performing similar tasks. In the same way, seeing similar others fail in the presence of high effort lowers the observers' efficacy beliefs (Bandura, 1982). Gaining information through vicarious experience has a weaker effect on efficacy than information gained through personal experience and performance. Thus, the effects of vicarious experience can be negated more easily by performance difficulties (Schunk, 1996). Schunk (1981) examined elementary school children learning division. Students received either modeling with explanatory pages, explanatory pages alone, or no treatment. Students in the modeling and explanatory pages groups also either received attributional feedback or did not receive attributional feedback. Increases in self-efficacy were found for students who received explanatory pages along with modeling or explanatory pages alone when compared to the control group who did not receive either one. There was no difference in groups based upon attributional feedback. People also gain efficacy information from physical reactions such as heart rate and sweating. Physical symptoms indicating anxiety may be interpreted as a lack of skill (Schunk, 1996).

Performances, vicarious experiences, physiological cues, and social persuasion do not influence self-efficacy directly. The effect of these upon self-efficacy depends on how the information is cognitively appraised (Bandura, 1977). The context in which the information is received plays a role in its appraisal. According to Bandura (1977, p. 200), “A number of contextual factors, including the social, situational, and temporal circumstances under which events occur, enter into such appraisals.” Schunk (1985, p. 5) described cognitive appraisal as "an inferential process in which persons weight 
and combine the contributions of personal and situational factors.” This is why even successful performances may not create strong expectations of personal efficacy (Bandura, 1977). Individuals attribute their success to outside situational factors rather than their ability, and this at times, is an inaccurate appraisal. The same holds true for failures and negative impacts upon self-efficacy. When forming efficacy judgments, people take into account a number of factors including perceived ability, task difficulty, amount of effort required, amount of help received, and past success and failures (Schunk, 1990). According to Schunk (1990), educational practices are one of these contextual factors. Certain educational practices serve to verify growing efficacy beliefs as an individual experiences success with a task. Other practices may not verify these beliefs, and may provide information that is unclear or even indicate a lack of skill.

The previously presented information all dealt with self-efficacy and performance. Efficacy beliefs can be measured for learning as well as performance behaviors. Bandura is regarded as the father of self-efficacy theory, but there was no mention of self-efficacy for learning in his original works on the subject. The problem with this is that when students are placed into learning or academic settings, they have little to no skill or ability. Therefore, self-efficacy is not a useful measure due to students' efficacy for performing a task being extremely lacking or completely nonexistent (Schunk, 1996). In contrast, students' efficacy for learning is likely to vary due to differing past experiences as well as perceptions of learning progress as they work on a task (Schunk, 1989a). Students who have previously done well in a particular content area are more likely to believe that they have the ability to further their learning. Students who have experienced difficulties may doubt their capabilities for further learning (Schunk, 1989b).

Self-efficacy for learning is important, especially in school settings. It is believed to be an important process in learning and motivation (Schunk, 1989a). It involves asking individuals to rate 
their capabilities to learn to do certain tasks (solve math problems, compose a song, or write a creative essay). When assessing learning ability, students may evaluate factors such as what they need to learn, what knowledge and skills are required for new learning, the ease of learning similar information in the past, ability to attend to instruction and rehearse information, amount of time to learn, and the ability to monitor their own learning (Schunk, 1996). According to Schunk (1996), students who feel more efficacious about learning should perform more proactive learning behaviors such as attending to instruction, rehearsing information, and monitoring level of understanding. Schunk (1989a) classified these as requiring cognitive effort, and they are a good indicator of motivation in learning settings.

The original hypothesis that self-efficacy influences effort, choice of activities, and persistence needs to be modified for learning scenarios. Students rarely have their choice of activities in school, and they persist longer regardless of their self-efficacy because the teacher keeps them on task (Schunk, 1989b). Praise from a teacher can affect self-efficacy because the praise reflects how the teacher views student ability. Students who feel that the teacher does not expect much of them are more likely to doubt their capabilities (Schunk, 1989b).

Judgment or appraisal of efficacy beliefs can be especially hard in academic and learning settings. To accurately judge self-efficacy, people must be able to distinguish between success and failure. It is much easier to judge efficacy for performance of previously learned skills or behaviors. People are usually able to determine if they have succeeded or failed in the past. Self-efficacy for learning is not so clearly judged. When learning complex tasks, students may learn some of the skills necessary while not learning others. Because students may not be aware of all of the skills and demands of a task, they may misjudge their capabilities. For example, it is possible to work mathematics problems using an incorrect strategy and get an incorrect solution. If the student is unaware that they are using an incorrect strategy, they may think they are correctly solving the 
problems. Their efficacy will be high, but their skill is actually very low (Schunk, 1989a).

The impact of efficacy beliefs on education and academic performance has been an area of major focus. Research has been conducted on groups with varying levels of education, from elementary school to undergraduate college students. In the past, self-efficacy has been shown to be a significant predictor of task performance (Locke et al, 1984), and more recent research also supports this notion.

Lent, Brown, and Larkin (1984) examined self-efficacy, academic performance, and persistence in college freshman and sophomores. They found that students who were more efficacious had significantly higher GPAs and persisted longer than students with low efficacy beliefs. It was found that all students who were rated at high-level or high-strength for efficacy beliefs completed all four academic quarters of the school year following the assessment. For those students who were either low-level or low-strength, only 58\% and 50\% completed all four of the following academic quarters. The measures used in this research were somewhat general and broad, yet they still found significant relationships between self-efficacy, performance, and persistence.

Choi (2005) investigated the relationship between self-efficacy and end of term grades in college students. The self-efficacy of these undergraduate students was measured using different levels of specificity. Students' overall global self-efficacy, general academic self-efficacy, and course specific self-efficacy were measured using self-report instruments. The regression analysis was found to be significant, and course specific self-efficacy was found to be a significant predictor of term grades. This supports the hypothesis that self-efficacy measures should be as specific to a task as possible when attempting to predict performance.

Research conducted with students in intermediate college French courses found similar results (Mills, Pajares, \& Herron, 2007). Students enrolled in intermediate French 1 or intermediate French 2 
at three institutions of higher learning completed multiple self-report questionnaires. The questionnaires assessed French grade self-efficacy, French learning anxiety, French learning selfconcept, and self-efficacy for self-regulated learning. Academic achievement was evaluated using students' final grade in an intermediate-level French course. Self-efficacy for self-regulated learning was found to be the most significant predictor of student achievement.

Hsieh, Sullivan, and Guerra (2007) found that self-efficacy is related to positive goal orientations. Among 112 undergraduate students, grade point average (GPA) was found to be positively related to both self-efficacy and mastery goal orientation. GPA was negatively related to performance-avoidance goal orientation. Regression analysis found that self-efficacy alone was a significant predictor of GPA. It was also found that students with higher self-efficacy adopted stronger mastery goals than those with lower self-efficacy. In a study of Bangladesh college students, Chowdhury and Shahabuddin (2007) found that self-efficacy was significantly positively correlated with motivation and academic performance. In a regression analysis, self-efficacy explained $15.6 \%$ of the variability in student performance.

Several meta-analytic research studies have been conducted which investigated self-efficacy and academic performance. Multon, Brown, and Lent (1991) performed a meta-analysis of 39 research studies conducted between 1977 and 1988. Numerous performance measures were included in the meta-analysis $(\mathrm{n}=19)$. Performance measures included standardized test scores, class grades, and basic skills assessments. The reported effect size between self-efficacy and academic performance was moderate $(r=0.38)$. There was also a moderate effect size for self-efficacy and persistence among 18 studies that were identified and examined $(r=0.34)$. These results suggest that self-efficacy beliefs account for about $14 \%$ of the variability in academic performance and about $12 \%$ of the variability in persistence. Larger effect sizes were found for high school and college students than for elementary 
school children and these results suggest that students who know more about themselves and their efficacy beliefs are better able to judge their capabilities. However, they also reported significant heterogeneity among the criterion measures and that may limit the conclusions that can be drawn.

Robbins et al (2004) conducted a meta-analytic investigation examining the predictive relationship among psychosocial and study skills factors and college performance and retention. A comprehensive literature search was performed including a computer search using the PsychINFO and ERIC databases (1984-2004). Searches of other journals were performed manually. A total of 109 different studies were selected for use in the research with a total of 476 correlations obtained (197 correlations with retention criterion and 279 correlations with GPA criterion). Psychosocial and study skills factors included achievement motivation, academic goals, academic self-efficacy, general selfconcept, and several other constructs. Positive correlations were found among academic self-efficacy, academic goals, academic related skills, and retention. Out of all the psychosocial and study skills factors, academic self-efficacy was found to be the best predictor of GPA. However, some of these variables (including academic self-efficacy) were based upon a small number of studies (6 to 8) possibly lessening the magnitude of the relationships.

Another construct very similar to self-efficacy is self-concept. Self-concept is a person's perception of himself (Bong \& Skaalvik, 2003). Though the two constructs are very similar, selfefficacy and self-concept differ in some important ways. Self-concept judgments call for an evaluation of the skills and abilities one possesses. Efficacy judgment is less concerned with the skills and abilities one possesses. Self-concept is measured at a broader level of specificity. While self-efficacy judgments are often task specific, self-concept judgments are not. Self-concept may be domain specific, but it is much less context dependent than self-efficacy (Pajares, 1996). The expectation that one can run 100 meters in 10 seconds is an efficacy judgment. It does not require a judgment of one's 
overall running ability. It is a judgment of how well that person can perform given the current circumstances. Self-concept is also associated with feelings of self-worth that are not involved in efficacy judgments. Self-efficacy and self-concept are not always related. It is possible to be very efficacious for some task and lack the feelings of self-worth associated with self-concept. This may occur if an individual takes no pride or has no interest in a task (Pajares, 1996). Self-concept, like selfefficacy, is believed to be a good predictor one's thoughts and behaviors in the classroom.

Bailey (1971) examined self-concept differences in low and high achieving students at West Virginia University. Underachieving students were randomly selected from courses for effective study. Achieving students were selected from an Introduction to Psychology course. Students were assessed using three measures: a self scale, an ideal self scale, and a test to assess college ability. High achievers with low ability viewed their ability as being significantly higher than underachievers with low ability. Achieving students with below average ability indicated a higher wished-for level of academic achievement than did underachievers with low ability.

In an examination of the relationship between academic self-concept and grade performance in college calculus, House (1995) found that self-rating of overall academic ability and self-rating of mathematics ability were significant predictors of grade performance. Similarly, Wilhite (1992) found that students' self-concept of academic ability was the best predictor of final course grades among selfefficacy, self-concept, study activity, and memory. In a longitudinal research study, House (1993) examined the relationship between academic self-concept and school withdrawal. Students' self-ratings of overall academic ability, drive to achieve, mathematical ability, writing ability, and self-confidence in intellectual ability were collected. The regression model based on these variables was found to be significant in predicting school withdrawal. However, no reliability or validity data for the self-report measures was presented in any of these research studies. 
Research has shown that self-concept and academic achievement are related. However, caution must be taken when attempting to predict performance using self-concept. Self-concept is a very general construct. As was previously discussed, such general, broad measures may not be as useful in predicting performance as more domain specific measures. Schunk (1987) suggests that perceptions of specific behaviors influence subarea self-concepts, which in turn influence academic self-concept. Higher correlations have been found between subject area self-concept and academic achievement than between academic self-concept and achievement.

Self-efficacy is also thought to be related to and have influence upon the degree to which individuals self-regulate their learning (Bandura, 1977). Self-regulated learning refers to the processes that individuals use to maintain the control, cognition, motivation, and behavior needed to achieve desired goals (Bembenutty, 2008). Self-efficacy is one of multiple processes that are thought to be part of self-regulated learning (Schunk, 1990). Self-regulatory learners exert more effort, persist longer, and use more cognitive and metacognitive strategies (Pajaraes, 2002; Bembenutty, 2008). Zimmerman (1990) described self-regulated learners as being aware when they possess certain knowledge or skills and when they do not. They seek out information or knowledge they do not have and attempt to master it. They find a way to be successful when presented with obstacles that may make learning difficult, and they self-instruct and self-reinforce during the learning process.

In Bandura's social cognitive theory, individuals are capable of monitoring their own behaviors and the consequences of those behaviors. Through these experiences, efficacy beliefs are formed. These beliefs are fundamental to the future goals and tasks the individuals pursue. Bandura (1993) found a significant relationship between perceived academic self-efficacy and academic achievement as well as between self-regulatory efficacy and academic achievement among students in grades 6 and 7. Bembenutty (2008) found self-regulation of learning to be positively correlated with self-efficacy, 
rehearsal and elaboration study strategies, and final course grades. It was also demonstrated that selfregulation and test anxiety were negatively correlated. A study of undergraduate students at a university in Jordan showed that students with high GPAs scored significantly higher on measures of self-efficacy, metacognitive self-regulation, intrinsic goal motivation, and time and study environment management (Al-Alwan, 2008). Self-efficacy, intrinsic goal orientation, and metacognitive selfregulation were all found to be highly correlated with each other. In another study, high self-regulation was associated with high self-efficacy and mastery and performance goals in college students (Shell \& Husman, 2008).

Schapiro and Livingston (2000) examined the difference between active self-regulation and dynamic self-regulation. Active self-regulation involves focused, deliberate control of cognitive processes. It calls upon the use of learning strategies such as rehearsal and elaboration. It would be considered to be the traditional representation of self-regulated learning. Dynamic self-regulated learning is more spontaneous and involves an internal force that drives interest, motivation, curiosity, and persistence. Differences in GPA were examined based upon type of self-regulation (active and dynamic). There was a significant main effect for dynamic regulation. Students who are higher dynamic regulators had higher GPAs.

There is a clear relationship between efficacy beliefs, task performance, academic achievement, and learning. There are numerous other research studies documenting these relationships. Pajares (2002) provides an extensive review of the literature supporting the relationship between self-efficacy and self-regulation in an effort to examine gender differences in these variables. The relationship between self-efficacy, performance, prosocial behaviors, and other variables has been well documented by Bandura (1977, 1993, \& 1996).

Self-efficacy has been identified as good predictor of academic performance. Research has 
suggested further research to determine what influences the development of self-efficacy. The purpose of the research is to determine if simply learning about learning strategies and the learning process has an influence upon the development of self-efficacy.

\section{Purpose of the Study}

Self-regulation is very important in the development of adult learners. Self-efficacy is related to and has an influence upon self-regulation. The purpose of this study was to determine if students enrolled in Educational Psychology 101 Learning Strategies for Academic Success (EDP 101) develop more positive efficacy beliefs as they learn about learning strategies covered in the course. Students in the EDP 101 class learn about memory, rehearsal and review strategies, note taking, and how to take tests. Students who do not take this course may not learn about these ideas through any of their normal coursework. Students have difficulties in college because they are not adequately prepared when they graduate from high school. They have not been exposed to the types of higher level thinking required for many college courses and exams. The EDP 101 course helps to teach these students such concepts. Past research has suggested evaluating what factors play a role in influencing the development of efficacy beliefs. The belief of the researcher is that learning about learning influences the development of efficacy for regulating one's learning. The hypothesis is that students in the EDP 101 course should develop more positive efficacy beliefs for regulating their learning as new concepts and strategies for learning are covered in the course. 


\section{Method}

\section{Participants}

Participants were 60 students enrolled in Educational Psychology 101 (EDP 101) at West Virginia University. These 60 students were spread across twelve sections of the course. Of the 60 participants, 39 were male and 21 were female. Initially, 118 students completed the assessment. However, due to absences and other circumstances, only 60 students completed all three assessments. Students were aged at least 18 years old. Most participants were in their first or second year of college, and most had demonstrated serious academic difficulties in the previous semester. Participants were not randomly selected. Convenience sampling was used, and all students in each classroom were asked to be part of the research.

\section{Setting}

Data collection took place in several different classrooms at West Virginia University. The settings for data collection were EDP 101 classrooms. There were approximately 10 to 20 students in each section of EDP 101. There were approximately eighteen sections of the course during the Spring 2010 semester, and twelve of those sections were part of the research. The classrooms were moderately sized, traditional style classrooms. There were desks for each student as well as desks used by the instructors.

\section{Measures}

Self-efficacy for learning was measured. Self-efficacy for learning was measured using the Self-Efficacy for Learning Form - Abridged (SELF-A). The SELF-A is a 19-item self-report survey 
designed to measure students' efficacy for self-regulating their learning. Students rated their ability for certain learning tasks (e.g., When a lecture is boring, I can motivate myself to keep good notes) on a scale from 0 (definitely cannot do it) to 100 (definitely can do it). Zimmerman and Kitsantas (2007) evaluated the SELF-A and found good reliability and validity. Predictive validity was established by assessing the relationship between scores on the measure and several variables including course grades $(\mathrm{r}=.58)$, perceived responsibility $(\mathrm{r}=.50)$, and homework quality $(\mathrm{r}=.55)$. The SELF-A was found to be a better predictor of most variables than the unabridged SELF. The reliability coefficient for the SELF-A was 0.97. The self-report nature of the SELF-A may lessen the instrument's validity. This is the case when assessing any construct that cannot be directly measured. Individuals tend to rate their ability higher than what it actually is.

\section{Procedures}

Each participant voluntarily completed the SELF-A, an instrument designed to measure selfefficacy for learning. Students were informed that all of their information would remain anonymous, and the process would take approximately 15 minutes. The SELF-A was be completed by each student following each of the three exams in the course during the first semester of classes in the Spring of 2010. The first assessment took place during the week of February $22^{\text {nd }}$ for all sections of the course. The second assessment took place during the week of March $15^{\text {th }}$ for students in sections meeting on Tuesday and Thursday and March $22^{\text {nd }}$ for students in sections meeting on Monday, Wednesday, and Friday. The second assessment took place a week later in the Monday, Wednesday, and Friday sections because the test was scheduled a week later in those sections. This was due to weather issues and class cancelations earlier in the semester. The final assessment took place during the week of April $19^{\text {th }}$ for all sections of the course. Participants were asked to include their name on the completed forms so that 
their scores on each assessment may be compared. This information was coded for the data analysis and report of the research results to maintain anonymity. Participants were informed that if they were not at least 18 years of age then they may not participate in the research. Participants were not randomly selected. All participants in each classroom were asked to participate. Twelve of the eighteen sections of EDP 101 participated in the research. Participants were asked to report their gender as well. The SELF-A was administered by the researcher in each classroom.

The researcher contacted the instructor in each EDP 101 classroom in order determine if their classroom would be part of the research. All instructors who were contacted agreed to allow the researcher to visit their classroom to ask students to participate. The researcher distributed and collected the assessment in each classroom. Students completed the assessments in their EDP 101 classroom during the first 15 minutes of the class period. They were given the following directions:

“This is a research project. I am asking for your participation. You are not required to participate, and you may choose not to participate. If you do not wish to participate please say so now. If you are under the age of 18, you may not participate. If you are under 18 years of age, please say so now.

If you wish to participate, rate how capable you are to complete each of the tasks on the following assessment. You will rate your ability on a scale from 0 (Definitely cannot do it) to 100 (Definitely can do it). You will be asked to complete this assessment a total of three (3) times during the semester. Please complete the form entirely. Do not leave items blank. Please take your time and read each item carefully. Please do not talk with other students in the class while completing the assessment. You must include your name or e-mail address on the assessment.

When you are finished, please return your assessment to the researcher. If you choose to participate, you will be entered into a drawing for three (3) \$75 Visa gift cards. The winners will be 
determined through random drawing. The winner will be contacted through e-mail. If you want the opportunity to win, you must include your name and e-mail address. You must also complete all three assessments to be eligible.”

It took approximately 15 minutes for students to complete the instrument each time. Students were informed that if they completed the instrument all three times, then they would be entered into a drawing for a chance to win one (1) of three (3) Visa Gift Cards valued at \$75 each. Upon completion of data collection, data were entered into SPSS and analyzed. Data were examined for changes in selfefficacy over the duration of the EPD 101 course. Self-efficacy scores for each item on the assessment were examined in regards to the material that was being covered at the time of each assessment. Selfefficacy should have been low for items that target information and strategies (such as note taking, time management, and studying) that were not covered at the time of that assessment. Self-efficacy should have been higher for those items after the targeted information was covered in the course. Data were analyzed through repeated measures analysis of variance (ANOVA) with post hoc analysis to determine when differences occurred.

\section{Results}

Results of the repeated measures ANOVA showed statistically significant differences in scores across assessments for item 1, item 2, and item 3 of the SELF-A. The mean scores for item 1 (When you miss a class, can you find another student who can explain the lecture notes as clearly as your teacher did?) for each of the three assessments were $56.350,66.167$, and $70.533(F(1.996,117.768)=$ 10.588, $p<.05$ ). The mean scores for item 2 (When your teacher's lecture is very complex, can you write an effective summary of your original notes before the next class?) for each of the three assessments were 59.167, 60.967, $70.917(F(1.683,99.291)=7.939, p<.05)$. The mean scores for item 3 (When a lecture is especially boring, can you motivate yourself to keep good notes?) for each of 
three assessments were $57.250,60.450$, and $64.500(F(1.838,108.455)=3.212, p<.05)$. The Greenhouse-Geisser value was reported for all statistics. The Greenhouse-Geisser is more conservative and adjusts for issues related to sphericity. There were no statistically significant differences among the other sixteen items of the SELF-A. Some items decreased slightly across the three assessments while others stayed relatively stable. Means and standard deviations of all items for assessments one, two, and three can be seen in Table 1. Results of repeated measures ANOVA for items 1, 2, and 3 can be seen in Table 2.

Post hoc analysis indicated that for item 1 , the mean difference was statistically significant between assessments 1 and 2 and assessments 1 and 3. For item 2, the mean difference was statistically significant between assessments 1 and 3 and assessments 2 and 3. For item 3, the mean difference was not statistically significant between any of the assessments. Results of the post hoc analysis can be seen in Table 3.

The data for each item across all assessments was not normally distributed. This was determined through the use of the Kolmogorov-Smirnov test. Because of this, parametric tests may not be accurate. Parametric tests use the mean and standard deviation in their calculations. When data is not normally distributed, the mean and standard deviation may not accurately represent the data. In these cases, it may be better to use non-parametric tests which utilize the median. Friedman's ANOVA, a non-parametric test, was used to confirm the findings of the repeated measures ANOVA for items 1, 2, and 3. Results of the Friedman test confirmed that there were significant differences for items 1 $\left(\chi^{2}(2)=11.514, p<.05\right)$ and $2\left(\chi^{2}(2)=14.806, p<.05\right)$. The differences in item 3 were not significant when using a non-parametric test. For item 3, mean scores on the first two assessments were more evenly distributed. However, there were more outliers on the third assessment which increased the mean. This is why differences were not found with non-parametric tests that examine the median. 
These results can be seen in Tables 4, 5, and 6.

\section{Discussion}

The differences across assessments for items 1 and 2 support the hypothesis that learning about learning positively influences self-efficacy for learning. The differences between assessments 2 and 3 for item 2 followed the introduction and use of multiple skills that targeted students' ability to rewrite and summarize their notes and textbooks. Students were taught skills that emphasized pulling out and summarizing important information from notes and textbooks for self-testing. General note taking strategies were also covered. These skills were covered approximately only one week before the second assessment and might explain why differences in self-efficacy were found between the second and third assessments. Characteristics of specific types of courses and the information that is important in those courses was covered between assessments two and three which may have also resulted in students' increased efficacy for these items. The steady increases in mean scores for item 1 is consistent with covering material in the course related to actively listening, lecture styles, and effective note taking, and working with study partners, . These results provide limited support that learning how to learn, through the course EDP 101, positively influences efficacy beliefs for regulating one's learning. After covering material related to note taking, active reading, and active listening, students showed increases in efficacy for two items related to note taking and summarizing information. While these results are statistically significant, they may not be practically significant. The differences in most participants' efficacy beliefs were consistent with the changes in mean scores which were at most fourteen points. Large increases in participants’ scores were rare. Suggestions for future research discussed later may provide more practically useful information.

Some limitations may have affected the results. First, the sample size was relatively small. 
Less than one half of all students enrolled in EDP 101 completed all three assessments. The students assessed may not have been an accurate representation of all students enrolled in the course. Larger effects must also be present to be detected when smaller samples are used. Second, the first data collection did not take place at the start of the course. A true baseline self-efficacy was never assessed. Students' self-efficacy may have increased during the time between the start of the course and the first assessment. Third, the amount of time between data collections was less than what was originally planned. There was approximately only one month between data collections rather than closer to two months. This may not have been enough time to allow for the development of students' efficacy beliefs. It must also be noted that those who completed all three assessments may have been students who already had relatively high efficacy beliefs, and there may be reliability issues with data that is self-reported. It is also possible that the differences that were found for the first items on the assessment were due to the primacy effect and for subsequent items possibly the boredom or fatigue associated with completing all 19 items. Despite these limitations, some statistically significant differences were still found.

The lack of increases and even the presence of decreases across assessments may also provide important information. Past research has suggested that the accuracy of individuals' efficacy appraisals may be inaccurate in learning settings (Schunk, 1989a). It is possible that students did very well in high school and attributed that success to their learning abilities. However, it is likely that the tasks students encountered in high school were very different from those they encounter at the college level. Most students in enrolled in the EDP 101 course have even done poorly at the college level and may have believed their performance was the result of some outside factors. By experiencing the course EDP 101, those beliefs are challenged and eventually changed. The students realize that they are not as capable as they once thought. So, although their efficacy beliefs remained relatively stable, those 
beliefs were a more accurate representation of their ability. This suggests that before educators can take the all important step of improving students' self-efficacy beliefs, they must first help students accurately judge their capabilities.

Students' efficacy beliefs along with the accuracy of those beliefs could be measured. An assessment that directly tests the abilities for which students are asked to rate their efficacy could be developed. Students would rate their efficacy for those abilities and then complete the assessment to compare their actual ability with how they rated their ability. There is also a lack of group comparisons in regards to developmental interventions related to self-efficacy. Future research might compare students in a course such as EDP 101 with students not enrolled in the course. Efficacy beliefs for both groups could be assessed throughout the semester and compared. Because students in classes such as EDP 101 often times have demonstrated some academic difficulties, statistical analysis could be used to control for other factors such as student GPA.

Further research could be conducted with the current data. Test scores for each exam could be obtained for all students. Those test scores could then be compared to scores on the efficacy assessment to determine if any correlations are present. Further research in the EDP 101 classroom might utilize a multiple baseline design across skills. Students' efficacy for items targeted by the learning skills taught in EDP 101 could be assessed frequently throughout the semester. As new skills are introduced, scores for items related to those skills should increase. If scores did increase, then it is likely that the introduction of those skills were responsible for the increases. These suggestions might offer some direction for future research. 
1. When you miss a class, can you find another student who can explain the lecture notes as clearly as your teacher did?

2. When your teacher's lecture is very complex, can you write an effective summary of your original notes before the next class?

3. When a lecture is especially boring, can you motivate yourself to keep good notes?

4. When you had trouble understanding your instructor's lecture, can you clarify the confusion before the next class meeting by comparing notes with a classmate?

5. When you have trouble studying your class notes because they are incomplete or confusing, can you revise and rewrite them clearly after every lecture?

6. When you are taking a course covering a huge amount of material, can you condense your notes down to just the essential facts?

7. When you are trying to understand a new topic, can you associate new concepts with old ones sufficiently well to remember them?

8. When another student asks you to study together for a course in which you are experiencing difficulty, can you be an effective study partner?

9. When problems with friends and peers conflict with schoolwork, can you keep up with your assignments?

10. When you feel moody or restless during studying, can you focus your attention well enough to finish your assigned work?

11. When you find yourself getting increasingly behind in a new course, can you increase your study time sufficiently to catch up?

12. When you discover that your homework assignments for the semester are much longer than expected, can you change your other priorities to have enough time for studying?

12. When you have trouble recalling an abstract concept, can you think of a good example that will help you remember it on the test?

14. When you have to take a test in a school subject you dislike, can you find a way to motivate your-self to earn a good grade?

15. When you are feeling depressed about a forthcoming test, can you find a way to motivate yourself to do well?

16. When your last test results were poor, can you figure out potential questions before the next test that will improve your score greatly?

17. When you are struggling to remember technical details of a concept for a test, can you find a way to associate them together that will ensure recall?

18. When you think you did poorly on a test you just finished, can you go back to your notes and locate all the information you had forgotten?

19. When you find that you had to "cram" at the last minute for a test, can you begin your test preparation much earlier so you won't need to cram the next time?

Std.
Std.

Mean

Deviation

Mean

Deviation

Mean

$56.3500 \quad 26.0018$

26.65102

Mean

$59.6167 \quad 24.35340$

60.9667

26.01366

$\begin{array}{ll}57.2500 & 25.62283\end{array}$

60.4500

23.84940

63.4167

27.17569

62.9667

24.47134

70.5333

22.90176

0.9167

19.69452

64.5000

66.5667

21.84809

65.0667

25.82986

68.0667

20.46648

67.5000

22.35803

74.1000

20.77866

73.1833

19.26223

72.7833

77.7333

74.2833

23.61994

75.0500

18.07932

$\begin{array}{ll}71.7000 & 22.93048\end{array}$

72.5833

20.77669

73.2000

$\begin{array}{ll}74.0167 & 22.02194\end{array}$

71.7667

22.52409

72.9833

$64.3167 \quad 24.53050$

61.8167

27.87471

61.9667

$67.3500 \quad 23.35854$

68.6000

22.76497

66.2167

73.8833

20.72589

73.0500

22.47139

73.03

70.283

21.59643

71.3833

19.47453

72.9833

22.11640

69.8333

21.51317

67.9500

22.00110

69.1667

22.61331

69.21

18.35356

67.7333

21.45778

71.4333

22.01646

65.7667

19.58994

69.9833

21.98034

72.9667

21.11708

77.1667

20.67043

71.8667

20.71556

72.2333

19.13854

73.5833

$77.9167 \quad 21.94700$

75.6167

24.15142

23.55973

76.0500

23.84727

71.8167

24.40929 
TABLE 2 Repeated Measures Analysis of Variance Results for Items 1, 2, and 3

\begin{tabular}{|c|c|c|c|c|c|c|c|}
\hline Source & Measu & & Type III Sum of Squares & df & Mean Square & $\mathrm{F}$ & Sig. \\
\hline \multirow[t]{12}{*}{ Assessment } & Item1 & Sphericity Assumed & 6332.033 & 2 & 3166.017 & 10.558 & .000 \\
\hline & & Greenhouse-Geisser & 6332.033 & 1.996 & 3172.243 & 10.558 & .000 \\
\hline & & Huynh-Feldt & 6332.033 & 2.000 & 3166.017 & 10.558 & .000 \\
\hline & & Lower-bound & 6332.033 & 1.000 & 6332.033 & 10.558 & .002 \\
\hline & Item2 & Sphericity Assumed & 4570.300 & 2 & 2285.150 & 7.939 & .001 \\
\hline & & Greenhouse-Geisser & 4570.300 & 1.683 & 2715.729 & 7.939 & .001 \\
\hline & & Huynh-Feldt & 4570.300 & 1.727 & 2646.719 & 7.939 & .001 \\
\hline & & Lower-bound & 4570.300 & 1.000 & 4570.300 & 7.939 & .007 \\
\hline & Item3 & Sphericity Assumed & 1584.100 & 2 & 792.050 & 3.212 & .044 \\
\hline & & Greenhouse-Geisser & 1584.100 & 1.838 & 861.759 & 3.212 & .048 \\
\hline & & Huynh-Feldt & 1584.100 & 1.895 & 836.157 & 3.212 & .047 \\
\hline & & Lower-bound & 1584.100 & 1.000 & 1584.100 & 3.212 & .078 \\
\hline \multirow[t]{12}{*}{ Error(Assessment) } & Item1 & Sphericity Assumed & 35385.967 & 118 & 299.881 & & \\
\hline & & Greenhouse-Geisser & 35385.967 & 117.768 & 300.471 & & \\
\hline & & Huynh-Feldt & 35385.967 & 118.000 & 299.881 & & \\
\hline & & Lower-bound & 35385.967 & 59.000 & 599.762 & & \\
\hline & Item2 & Sphericity Assumed & 33964.367 & 118 & 287.834 & & \\
\hline & & Greenhouse-Geisser & 33964.367 & 99.291 & 342.069 & & \\
\hline & & Huynh-Feldt & 33964.367 & 101.880 & 333.376 & & \\
\hline & & Lower-bound & 33964.367 & 59.000 & 575.667 & & \\
\hline & Item3 & Sphericity Assumed & 29100.567 & 118 & 246.615 & & \\
\hline & & Greenhouse-Geisser & 29100.567 & 108.455 & 268.320 & & \\
\hline & & Huynh-Feldt & 29100.567 & 111.776 & 260.348 & & \\
\hline & & Lower-bound & 29100.567 & 59.000 & 493.230 & & \\
\hline
\end{tabular}


TABLE 3 Post Hoc Analysis Results

\begin{tabular}{|c|c|c|c|c|c|c|c|}
\hline \multirow[t]{2}{*}{ Measure } & \multirow[t]{2}{*}{ (I) Assessment } & \multirow[t]{2}{*}{ (J) Assessment } & \multirow{2}{*}{$\begin{array}{l}\text { Mean Difference (I- } \\
\text { J) }\end{array}$} & \multirow[b]{2}{*}{ Std. Error } & \multirow[b]{2}{*}{ Sig. $^{a}$} & \multicolumn{2}{|c|}{$95 \%$ Confidence Interval for Difference ${ }^{a}$} \\
\hline & & & & & & Lower Bound & Upper Bound \\
\hline \multirow[t]{6}{*}{ Item1 } & 1 & 2 & $-9.817^{*}$ & 3.152 & .009 & -17.583 & -2.050 \\
\hline & & 3 & $-14.183^{*}$ & 3.106 & .000 & -21.837 & -6.530 \\
\hline & 2 & 1 & $9.817^{*}$ & 3.152 & .009 & 2.050 & 17.583 \\
\hline & - & 3 & -4.367 & 3.226 & .543 & -12.316 & 3.583 \\
\hline & 3 & 1 & $14.183^{*}$ & 3.106 & .000 & 6.530 & 21.837 \\
\hline & & 2 & 4.367 & 3.226 & .543 & -3.583 & 12.316 \\
\hline \multirow[t]{6}{*}{ Item2 } & 1 & 2 & -1.350 & 3.190 & 1.000 & -9.212 & 6.512 \\
\hline & & 3 & $-11.300^{*}$ & 3.588 & .008 & -20.141 & -2.459 \\
\hline & 2 & 1 & 1.350 & 3.190 & 1.000 & -6.512 & 9.212 \\
\hline & - & -3 & $-9.950^{*}$ & 2.394 & .000 & -15.849 & -4.051 \\
\hline & 3 & 1 & $11.300^{*}$ & 3.588 & .008 & 2.459 & 20.141 \\
\hline & & 2 & $9.950^{*}$ & 2.394 & .000 & 4.051 & 15.849 \\
\hline \multirow[t]{6}{*}{ Item3 } & 1 & 2 & -3.200 & 3.157 & .945 & -10.979 & 4.579 \\
\hline & & 3 & -7.250 & 2.970 & .053 & -14.570 & .070 \\
\hline & 2 & 1 & 3.200 & 3.157 & .945 & -4.579 & 10.979 \\
\hline & - & -3 & -4.050 & 2.423 & .300 & -10.021 & 1.921 \\
\hline & 3 & 1 & 7.250 & 2.970 & .053 & -.070 & 14.570 \\
\hline & & 2 & 4.050 & 2.423 & .300 & -1.921 & 10.021 \\
\hline
\end{tabular}

Based on estimated marginal means

*. The mean difference is significant at the .05 level.

a. Adjustment for multiple comparisons: Bonferroni. 
TABLE 4 Results of

Friedman Test for Item 1

\begin{tabular}{lr}
$\mathrm{N}$ & 60 \\
Chi-square & 11.514 \\
df & 2 \\
Asymp. Sig. & .003 \\
\hline
\end{tabular}

a. Friedman Test

TABLE 5 Results of

Friedman Test for Item 2

\begin{tabular}{lr}
$\mathrm{N}$ & 60 \\
Chi-square & 14.806 \\
df & 2 \\
Asymp. Sig. & .001 \\
\hline
\end{tabular}

a. Friedman Test

TABLE 6 Results of

Friedman Test for Item 3

N

60

Chi-square

2.268

df

2

Asymp. Sig.

.322

a. Friedman Test 


\section{References}

Al-Alwan, A. (2008). Self-Regulated learning in high and low achieving students at Al- Hussein Bin Talal University (AHU) in Jordan. International Journal of Applied Educational Studies, 1(1), 1-13. Retrieved September 22, 2009, from Education Research Complete database.

Bailey, R. (1971). Self-Concept differences in low and high Achieving Students. Journal of Clinical Psychology, 27(2), 188-191. Retrieved September 22, 2009, from Academic Search Complete database.

Bandura, A. (1977). Self-efficacy: Toward a unifying theory of behavioral change. Psychological Review, 84(2), 191-215. Retrieved September 22, 2009, doi:10.1037/0033-295X.84.2.191

Bandura, A. (1982). Self-efficacy Mechanism in human agency. American Psychologist, 37(2), 122147. http://search.ebscohost.com.www.libproxy.wvu.edu, doi:10.1037/0003-066X.37.2.122d

Bandura, A. (1984). Recycling misconceptions of perceived self-efficacy. Cognitive Therapy and Research, 8(3), 231-255. doi:10.1007/BF01172995.

Bandura, A. (1993). Perceived self-efficacy in cognitive development and functioning. Educational Psychologist, 28(2), 117. Retrieved September 22, 2009, from Academic Search Complete database.

Bandura, A., \& Barbaranelli, C. (1996). Multifaceted impact of self-efficacy beliefs on academic functioning. Child Development, 67(3), 1206-1222. Retrieved September 22, 2009, doi:10.1111/1467-8624.ep9704150192

Bandura, A., \& Cervone, D. (1983). Self-evaluative and self-efficacy mechanisms governing the motivational effects of goal systems. Journal of Personality and Social Psychology, 45(5), 1017-1028. http://search.ebscohost.com, doi:10.1037/0022-3514.45.5.1017 
Bandura, A., \& Schunk, D. (1981). Cultivating competence, self-efficacy, and intrinsic interest through proximal self-motivation. Journal of Personality and Social Psychology, 41(3), 586-598. http://search.ebscohost.com, doi:10.1037/0022-3514.41.3.586

Bembenutty, H. (2008). Self-regulation of learning and test anxiety. (Cover story). Psychology Journal, 5(3), 122-139. Retrieved September 22, 2009, from Academic Search Complete database.

Bong, M., \& Skaalvik, E. (2003). Academic self-concept and self-efficacy: How different are they really?. Educational Psychology Review, 15(1), 1-40. Retrieved September 22, 2009, from Academic Search Complete database.

Choi, N. (2005). Self-efficacy and self-concept as predictors of college students' academic performance. Psychology in the Schools, 42(2), 197-205. Retrieved September 22, 2009, doi:10.1002/pits.20048

Chowdhury, M., \& Shahabuddin, A. (2007). Self-efficacy, motivation and their relationship to academic performance of Bangladesh college students. College Quarterly, 10(1), 1-9. (ERIC Document Reproduction Service No. EJ813750) Retrieved September 22, 2009, from ERIC database.

Eastman, C., \& Marzillier, J. (1984). Theoretical and methodological difficulties in Bandura's selfefficacy theory. Cognitive Therapy and Research, 8(3), 213-229. doi:10.1007/BF01172994.

Finney, S., \& Schraw, G. (2003). Self-efficacy beliefs in college statistics courses. Contemporary Educational Psychology, 28(2), 161. http://search.ebscohost.com, doi:10.1016/S0361476X(02)00015-2 
Hsieh, P., Sullivan, J., \& Guerra, N. (2007). A closer look at college students: Self-efficacy and goal orientation. Journal of Advanced Academics, 18(3), 454-476. Retrieved September 22, 2009, from Academic Search Complete database.

House, J. (1993). The relationship between academic self-concept and school withdrawal. Journal of Social Psychology, 133(1), 125-127. Retrieved September 22, 2009, from Business Source Premier database.

House, J. (1995). The predictive relationship between academic self-concept, achievement expectancies, and grade performance in college calculus. Journal of Social Psychology,135(1), 111-112. Retrieved September 22, 2009, from Academic Search Complete database.

Lent, R., Brown, S., \& Larkin, K. (1984). Relation of self-efficacy expectations to academic achievement and persistence. Journal of Counseling Psychology, 31(3), 356-362. http://search.ebscohost.com, doi:10.1037/0022-0167.31.3.356

Locke, E., Frederick, E., Lee, C., \& Bobko, P. (1984). Effect of self-efficacy, goals, and task strategies on task performance. Journal of Applied Psychology, 69(2), 241-251. Retrieved September 22, 2009, from Business Source Premier database.

Mills, N., Pajares, F., \& Herron, C. (2007). Self-efficacy of college intermediate French students: Relation to achievement and motivation. Language Learning, 57(3), 417-442. Retrieved September 22, 2009, doi:10.1111/j.1467-9922.2007.00421.x

Multon, K., Brown, S., \& Lent, R. (1991). Relation of self-efficacy beliefs to academic outcomes: A meta-analytic investigation. Journal of Counseling Psychology, 38(1), 30-38. http://search.ebscohost.com, doi:10.1037/0022-0167.38.1.30 
Pajares, F. (1996a). Assessing self-efficacy beliefs and academic outcomes: The case for specificity and correspondence. Paper presented at the Annual Meeting of the American Educational Research Association (New York, NY, April 8-12, 1996). http://search.ebscohost.com http://search.ebscohost.com

Pajares, F. (1996b). Self-efficacy beliefs in academic settings. Review of Educational Research, 66(4), 543. http://search.ebscohost.com

Pajares, F. (2002). Gender and perceived self-efficacy in self-regulated learning. Theory Into Practice, 41(2), 116. Retrieved September 22, 2009, from Business Source Premier database.

Pajares, F., \& Miller, M. (1995). Mathematics self-efficacy and mathematics performances: The need for specificity of assessment. Journal of Counseling Psychology, 42(2), 190-198. http://search.ebscohost.com, doi:10.1037/0022-0167.42.2.190

Robbins, S., Lauver, K., Le, H., Davis, D., Langley, R., \& Carlstrom, A. (2004). Do psychosocial and study skill factors predict college outcomes? A meta-analysis. Psychological Bulletin, 130(2), 261-288. http://search.ebscohost.com, doi:10.1037/0033-2909.130.2.261

Schunk, D. (1981). Modeling and attributional effects on children's achievement: A self-efficacy analysis. Journal of Educational Psychology, 73(1), 93-105. http://search.ebscohost.com, doi:10.1037/0022-0663.73.1.93

Schunk, D. (1985). Self-efficacy and classroom learning. Psychology in the Schools, 22(2), 208-223. http://search.ebscohost.com, doi:10.1002/1520-6807(198504)22:2<208::AIDPITS2310220215>3.0.CO;2-7 
Schunk, D. (1987). Self-Efficacy and Cognitive Achievement. Paper presented at the Annual Meeting of the American Psychological Association (New York, NY, August 28-September 1, 1987). Retvrieved from ERIC database.

Schunk, D. (1989a). Self-efficacy and achievement behaviors. Educational Psychology Review, 1(3), 173-208. http://search.ebscohost.com, doi:10.1007/BF01320134

Schunk, D. (1989b). Self-efficacy and cognitive achievement: Implications for students with learning problems. Journal of Learning Disabilities, 22(1), http://search.ebscohost.com

Schunk, D. (1990). Goal setting and self-efficacy during self-regulated learning. Educational Psychologist, 25(1), 71. Retrieved from Education Research Complete database.

Schunk, D. (1991). Self-efficacy and academic motivation. Educational Psychologist, 26(3/4), 207. http://search.ebscohost.com

Schunk, D. (1996). Self-efficacy for learning and performance. Paper presented at the Annual Conference of the American Educational Research Association (New York, NY, April 8-12, 1996). Retrieved from ERIC database.

Shell, D., \& Husman, J. (2008). Control, motivation, affect, and strategic self-regulation in the college classroom: A multidimensional phenomenon. Journal of Educational Psychology, 100(2), 443-459. Retrieved September 22, 2009, doi:10.1037/0022-0663.100.2.443

Schapiro, S., \& Livingston, J. (2000). Dynamic self-regulation: The driving force behind academic achievement. Innovative Higher Education, 25(1), 23-35. Retrieved September 22, 2009, from Education Research Complete database.

Wilhite, S. (1992). Self-concept of academic ability, self-assessment of memory ability, academic aptitude, and study activities as predictors of college course achievement. (ERIC Document Reproduction Service No. ED350308) Retrieved September 22, 2009, from ERIC database. 
Zimmerman, B. (1990). Self-regulated learning and academic achievement: An overview.

Educational Psychologist, 25(1), 3. Retrieved from Education Research Complete database.

Zimmerman, B., \& Kitsantas, A. (2007). Reliability and validity of self-efficacy for learning form

(SELF) scores of college students. Zeitschrift für Psychologie/Journal of Psychology, 215(3), 157-163. doi:10.1027/0044-3409.215.3.157.

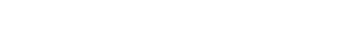

John H. 